\title{
COMPARISON OF REP RAP AND DAVINCI OSD REPOSITORIES: IS ANY INFLUENCE FROM ACADEMIC ORIGIN?
}

\author{
Affonso, Claudia Andressa Cruz (1); Atayde, Gisele Rodrigues (2); Amaral, Daniel (2) \\ 1: Federal Institute of Education; 2: University of Sao Paulo, Integrated Engineering Group
}

\begin{abstract}
The open source design (OSD) is an autonomous community dedicated to design new hardware products, peer-to-peer, with collaborative design and intellectual property copyleft, using web platforms to share projects. The research about these platforms indicates absence of important configuration management features as versioning, headlines and coding. One possible explanation for such finding is that these products are developed by non-designers. This argument was investigated comparing projects from two OSD communities, on the same theme, but with different origins. The hypothesis is that academically-influenced communities present better design management practices for repositories than others created by non-specialists. The hypothesis was not verified and the results show that there is no difference in the proportion of BO types or level of detail. However, it was identified five distinct characteristics: those of academic origin the communication is better detailed, the purpose is associated with methodological support, the structure of information promotes redundancy, the target-audience is the technicians and the success of project is associated with the number of interactions.
\end{abstract}

Keywords: Collaborative design, Open Source Design, Design management, Platform strategies, Repositories.

\section{Contact:}

Amaral, Daniel

University of Sao Paulo

Industrial Engineering

Brazil

amaral@sc.usp.br

Cite this article: Affonso, C.A.C., Atayde, G.R., Amaral, D. (2019) 'Comparison of Rep Rap and Davinci OSD Repositories: Is any Influence from Academic Origin?', in Proceedings of the 22nd International Conference on Engineering Design (ICED19), Delft, The Netherlands, 5-8 August 2019. DOI:10.1017/dsi.2019.10 


\section{INTRODUCTION}

The Open Source Software (OSS) initiatives are well recognized (de Jong; Bruijn, 2013) and were pioneer in the field of products created by crowd and distributed developers. Recently, we are facing a similar trend in product development. RepRap, E-nable, Open Source Ecology are examples of this phenomenon (Panchal; Fathianathan, 2008; Bruijn, 2010) that has received the title of Open Source Design or OSD (Affonso and Amaral, 2015).

These initiatives start at the end of the last decade (Panchal; Fathianathan, 2008; Bruijn, 2010) and are increasing. The Open Source Design means the development in a collaborative way, which consumer and designer are difficult to distinguish, and peer-to-peer participation can be seen in cooperative ventures (Benkler, 2006).

Affonso and Amaral (2015) highlight one main difference between software and hardware environment, the capacity to represent and reproduce the stored information. While software is pure information, that can easily be organized, downloaded and replicable by any network peer, hardware products demand a combination of physical prototyping and abstract information. The results must be decoded by those members (user and or developer) interested on try or build the final product. The software communities otherwise easily share the products through Control Versioning Systems (CVS) that integrated all information about product and versions in a practice and downloadable manner.

Pinfield (2009) defines repository as "a set of systems and services that facilitate the ingest, storage, management, retrieval, display, and reuse of digital objects". Pinfield et al. (2014) described several advantages for open access in repositories and Suber (2012) classifies in two types of repositories:

Gratis and Open Access is free of charge but not freer than that. It is a type of repository that removers price barriers but not permission barriers;

Libre Open Access is free of charge and also free of some copyright and licensing restrictions.

Bonvoision and Boujut (2015) analysed the current state of OSDs platforms (repositories), comparing them with theoretical requirements, and demonstrated problems related to them. According to the authors, the functionalities of these repositories were considered limited to basic functions like "file data" which would be insufficient to support a collaborative development.

One possible explanation, informally discussed at specialized forums, is the nature of OSDs community members. The OSDs are composed by regular people, not formal and not trained engineers or designers. This could explain the lack of more rigorous product development methods and formal configuration management $(\mathrm{CM})$ practices. In this point of view, the people who are creating these repositories could ignore the functionalities and their importance. Other possible explanation is the insufficiency of current configuration management practices by themselves. In this case, the OSD would be so distinct of traditional product development process that regular CM practices as versioning, bill of material control and auditing, read lines and others would be not useful and, consequently, it would not be appropriate.

We noted the existence of communities initiated and with strong academic relationship. Communities like RepRap, for example, were establish inside academy and maintain members originated of this environment, consequently, who received formal trained as engineers and designers. If the first hypothesis is correct, projects developed by them should present greater rigor in sharing and using BOs than regular communities. Therefore it is expected differences among the use of repositories.

This research classified the communities in academics and non-academics. It was found three central points in the open design literature:

- Configuration Management of repositories: Bonvoision and Boujut (2015) categorized different repositories. They noted that the functionalities of these repositories were limited.

- Boundary Objects: the literature showed that the appropriated use of boundary objects is differential in the dissemination of knowledge to amateurs and professionals (Star and Griesemer, 1989; Broberg, Andersen and Seim, 2011).

- Communities OSD: they aim to facilitated through the repositories the replicability by any network peer to build the final product (Affonso and Amaral, 2015; Bonvoision and Boujut, 2015; Bruijn 2010; Füller-Seitz and Reger, 2010). Therefore, the communities OSD should explore BO's in repositories in order to be effective.

The first communities OSD were originated at the academy as RepRap (Bruijn, 2010). The projects developed by them should present greater rigor in sharing and using BOs than regular communities 
(non-academic) as DaVinci Printer Owners, which was originated at Thingiverse, a repository with limited functionalities according to Bonvoisin, Boujut (2015).

Then we decide to investigate and compare two communities with similar subject and objectives but with different origins, academic and non-academic. We examined RepRap community (CC-BY-SA licence) and Da Vinci Printers Owners, both available in Thingiverse (Santoso and Wicker, 2014). The main objective of this article is to investigate and compare the BOs used to contribute to the OSD communities, analysing if the origin of the community can generate a pattern in the use of $\mathrm{BO}$ that differs from the other OSD.

The basic questions which motivated our research are both. Are there differences between the use of Boundary Objects (BOs) in an Open Source Design (OSD) Academic in relation others OSD communities? What are the main BOs in OSD communities and OSD Academic communities?

\section{OPEN SOURCE DESIGN}

The "open source" phenomena gained relevance with software, the phenomenon called Open Source Software (OSS). The idea focuses on allow the users freedom to share and change software. The source code is freely accessible to worldwide community of users and developers. The increasing interest in open source software was motivated by the success of products as Linux and Apache (Fuggetta, 2003). Principles similar to those of individuals of OSS guide the concept of OSD.

The main difference is that the concept of OSD is associated with the development of open-source physical products. It is note that little is discussed about the viability of the development for physical objects (Bruijn, 2010).

Affonso e Amaral (2015) identified some of terms that are used for this development between users and collaboration via the web, where few characteristics differentiate these terms. Some terms described by the authors were: communities of creation, co-creation, user-communities, open-source software, open-source development, commons-based peer production. Through this framework of concepts, OSD is composed for the elements indicated in Figure 1.

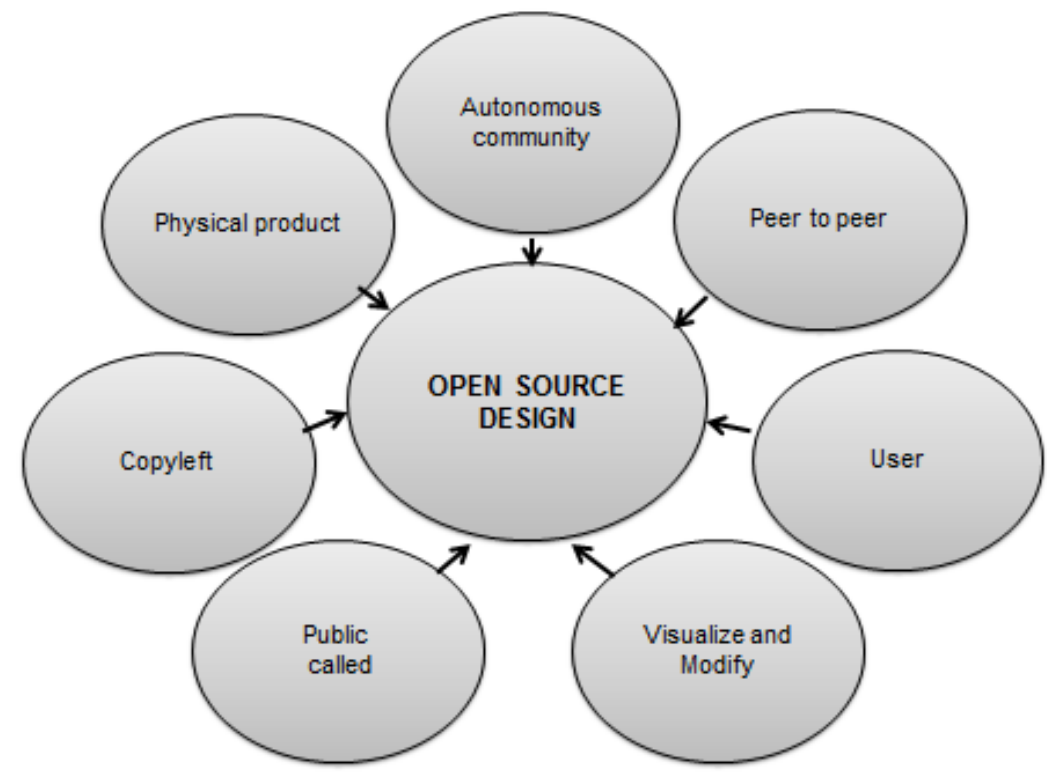

Figure 1. Definition of OSD

The current paper uses the definition of Affonso and Amaral (2015) OSD is an autonomous community in which the user plays a central role in the design, the network architecture is peer-topeer, the people involved are allowed to modify contributions from others, the call for participation of people in the development of a project is made public, the regime on intellectual property is copyleft, and the result of the final design should still be a physical product. 


\section{ACADEMIC SPIN-OFFS}

Academic spin-offs are new companies created to exploit intellectual property created in an academic institution (Shane, 2003). There are three types of academic spin-offs: (1) companies made up of university professors or researchers; (2) companies founded by university licensing to commercially exploit the results of research conducted in academia; (3) companies managed by people outside the university who decide to commercially exploit the results of academic research (Sánchez and Perez and, 1995).

According to Etzkowitz (2008), as industries shrink in size, the knowledge-based company as the academic spin-off, is emerging as a substantial engine of economic growth.

These models of firms are highly dependent on state-of-the-art technology and are often based on highly sophisticated science or engineering, rather than the presumption of market competition (Shane, 2003; Perez, Sanchez, 2003).

The probability of success in this model depends very much on the entrepreneurial ability of the scientists, which if deficient can be a barrier to the sharing of these inventions to the common market (Sijde et al., 2008).

In the study on OSD communities found in the literature, some are identified that were born within the universities. This demonstrates a new path of insertion and sharing of knowledge and inventions created in the academic environment for diverse audiences and places. There are no studies on this, but it is possible that they have more rigor and more intensive use of design management practices. This could include the practices of design management and the use of boundaries objects.

\section{BOUNDARY OBJECTS}

Boundary Objects can be abstract or concrete. BOs are objects shared and shareable across different contexts of problem (Carlile, 2002). They have different meanings in the diverse social worlds, but their structure is sufficiently common so that more than one world makes them a recognizable meaning in translation (Star and Griesemer, 1989). They are adaptable objects to the local needs and constraints of the several parties that employ them, and are robust enough to maintain a common identity across sites (Affonso and Amaral, 2015).

The literature shows the types of BOs. These classifications have some differences among the authors. The types of BOs are illustrated in Figure 2.

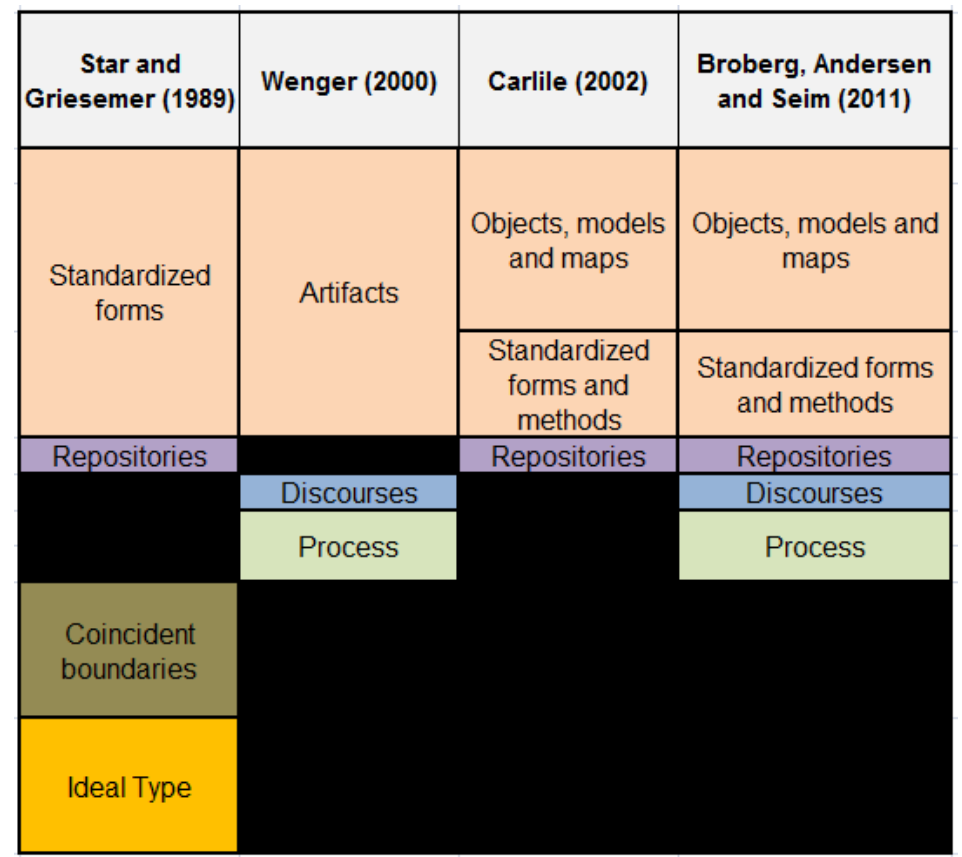

Figure 2. Types of boundary objects 
The Figure 2 shows a pattern in the classification of the identified authors. The same color in the cell represents this pattern. The dark cells indicate that the author of the column did not mention the dimension that is representing in the others authors.

In their research, Star and Griesemer (1989) identified four types of boundary objects: repositories, ideal type, coincident boundaries and standardized forms:

- Standardized forms refer to objects as methods of common communication across dispersed, thus corresponding to what Wenger (2000) points out as artifacts, Carlile (2002) and Broberg, Andersen and Seim (2011) inferred as objects, models and maps.

- Repositories refer to "stacks" of objects that are indexed in a standardized form, such as museums and libraries. Repositories are recognized to three authors.

- Coincident boundaries are common objects that have the same boundaries but different internal contents.

- Ideal types are objects, such as charts and atlases, which do not accurately describe the details of any place or thing.

Wenger (2000) and Broberg, Andersen and Seim (2011) add discourses and process:

- Discourses refer to the existence of a common language that allows the members of a context to communicate and negotiate meanings across the boundaries (Wenger, 2000; Broberg, Andersen and Seim, 2011).

- Process includes explicit procedures and routines in an organization. A business process, for instance, it acts as a $\mathrm{BO}$ to allow multiple practices to coordinate their contributions (Wenger, 2000; Broberg, Andersen and Seim, 2011).

This study specifically investigates objects, models and maps as BO. The justification is that these objects are regarded as essential to collaboration but difficult to share in a virtual environment. So, they are shared in different forms like videos, photos, sketch, codes, for instance. The next section will indicate the BOs investigated.

\section{METHOD}

The communities that are objects of this research are RepRap and DaVinci Printer Owners. They are available on Thingiverse. RepRap is available on Wikipage too. RepRap is an OSD created by Professor Adrian Bowyer in 2004 within the University of Bath whose aim was to collaboratively develop a low-cost device that could, to a large extent, produce a copy of itself and be accessible to anyone (Bruijn, 2010).

RepRap was initially built with less than 500 euros, which allowed several people to test the technology and improve it. The RepRap machine is described several times as a 3D printer, because based on digital design files; these machines can manufacture a range of physical objects of value to the user (Bruijn, 2010).

Da Vinci Printers Owners is a community with similar objective but with a origin not relationed with the university. It is a community of amateurs which uses Thingiverse as a repository.

This work will compared the differences the projects of these two communities. The first one considered as academic origin and the second as amateur or regular one. The Hypotheses of this research were stated as follows:

- $\quad \mathrm{H} 1$ - The frequency of BO's types, at the same platform, is not similar between overall projects from academic and non-academic OSDs.

- $\quad \mathrm{H} 2$ - The frequency of BO's types and the detail level, in distinct platforms, is not similar between projects from academic and non-academic OSDs.

Each hypothesis was analyzed as shown in Figure 3. 


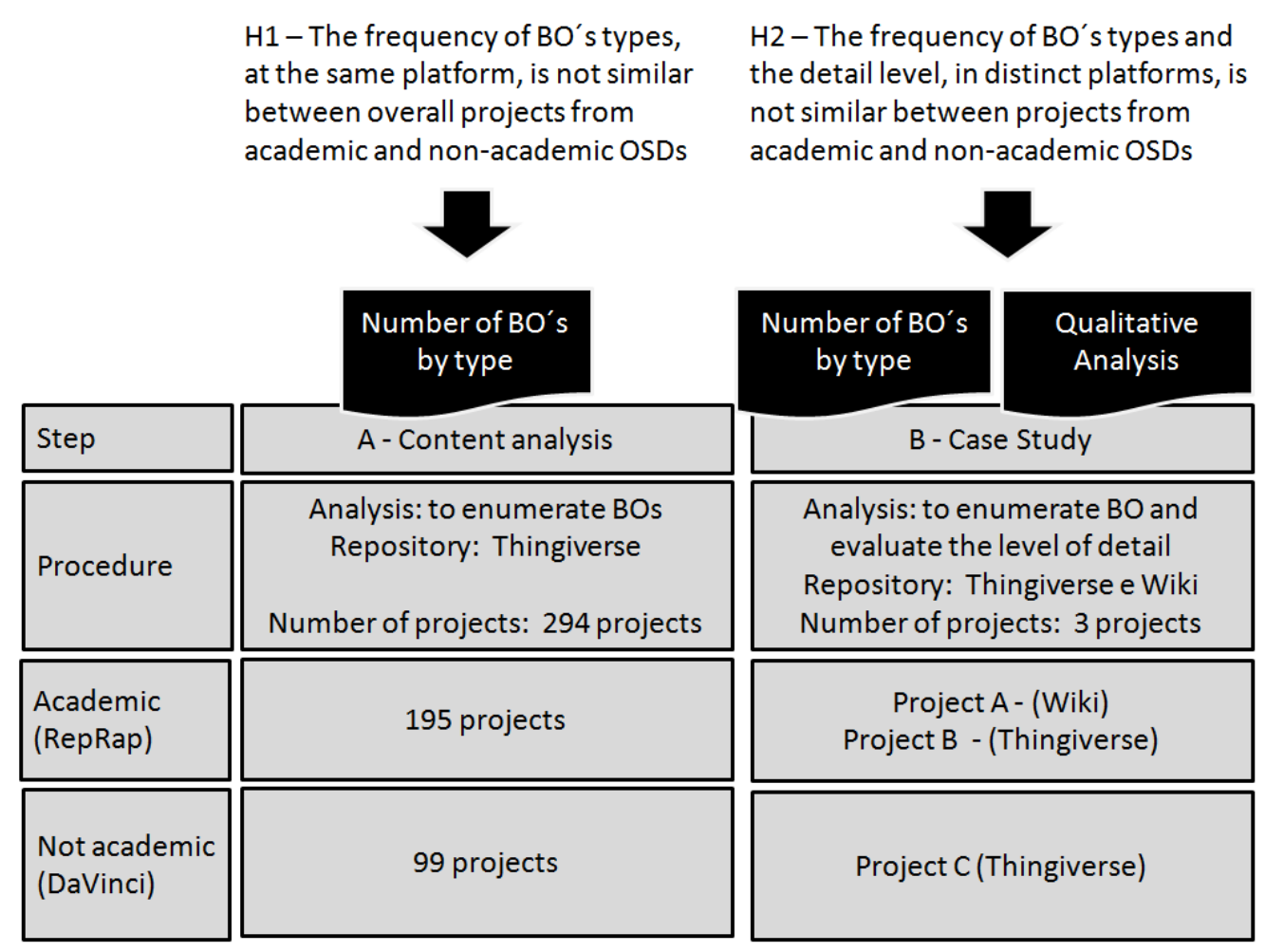

Figure 3. Method

From the two hypotheses, two analysis methods were used: content analysis and case study. The content analysis aims to identify and to enumerate the BOs inside the same repository Thingiverse for the projects of the communities RepRap (195 projects) and DaVinci Printers Owners (99 projects). The case study enumerated the BOs and evaluated the level of BOs`detail in two distinct repositories, Thingiverse and Wiki. So, three projects were analysed, project A and B of RepRap and Project C of Da Vinci. The selected projects were chosen by the similarity of their functions.

The hypothesis (H1) was analysed using 294 projects of both communities, all of them stored at an unique platform, Thingiverse. It was enumerate the total quantity of each BO type at 195 projects from RepRap (N=195) and 99 projects from DaVinci Printers Owners (N=99). In total 294 projects available on Thingiverse. Distinction between the profiles of BO frequencies between communities was the main interest. The BOs considered were video, photo, sketch/CAD, code, text, software and gif.

For a more detailed analysis we choose similar projects from both communities and considering different platforms. This step was classified as a case study because the content and history of the project was considered. The project is a belt-driven, gear based, open-source extruder design intended for 3D Printers. The project can be seen at Figure 4 .

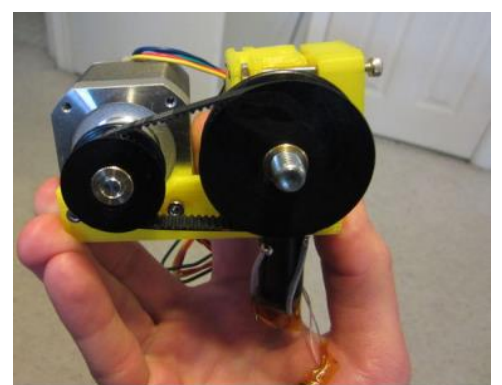

(a) Project A - RepRap - <Beltdriven> - RepRap Wiki (2015) (RepRap)

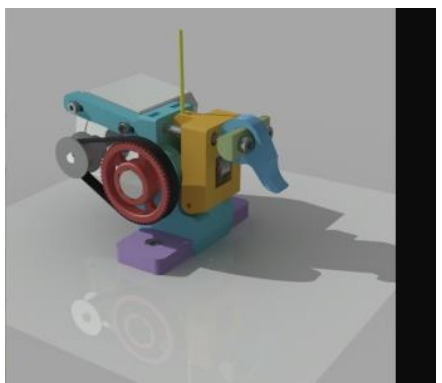

(b) Project B - RepRap <Compact Belt Drive Extruder> - Thingiverse (2016a) (RepRap)

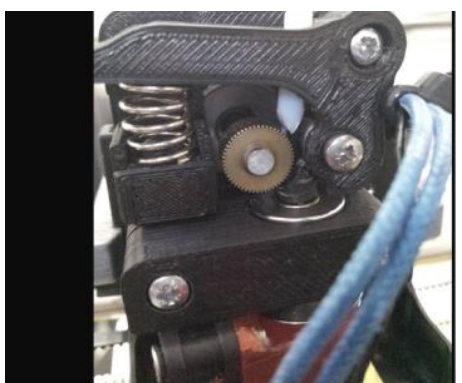

(c) Project C - DaVinci <Davinci E3d Mount With Extruder Upgrade> Thingiverse (2016b)

Figure 4. Projects - Gear based, open source extruder 
We observed the differences between the boundary objects of three projects with the same functionality: Project (A) made by an OSD academic spin-off and available on the community's wiki; Project (B) made by the same community of Project A, but it was analysed the project available on the Thingiverse; and Project (C) made by a user of OSD available on the Thingiverse. The intention was to verify $\mathrm{H} 2$. The analysis include the variables: number of the videos, number of photos, number of sketch/CAD, number of code lines, number of characters, number of software, number of gif and number of others links.

\section{RESULTS AND ANALYSIS}

The investigation of 294 projects at Thingiverse indicates the pattern illustrated in Figure 5. The hypothesis 1 (H1) states that the frequency of BO's types, at the same platform, is not similar between overall projects from academic and non-academic OSDs. The Figure 1 demonstrated the opposite and it is not possible agree with it.

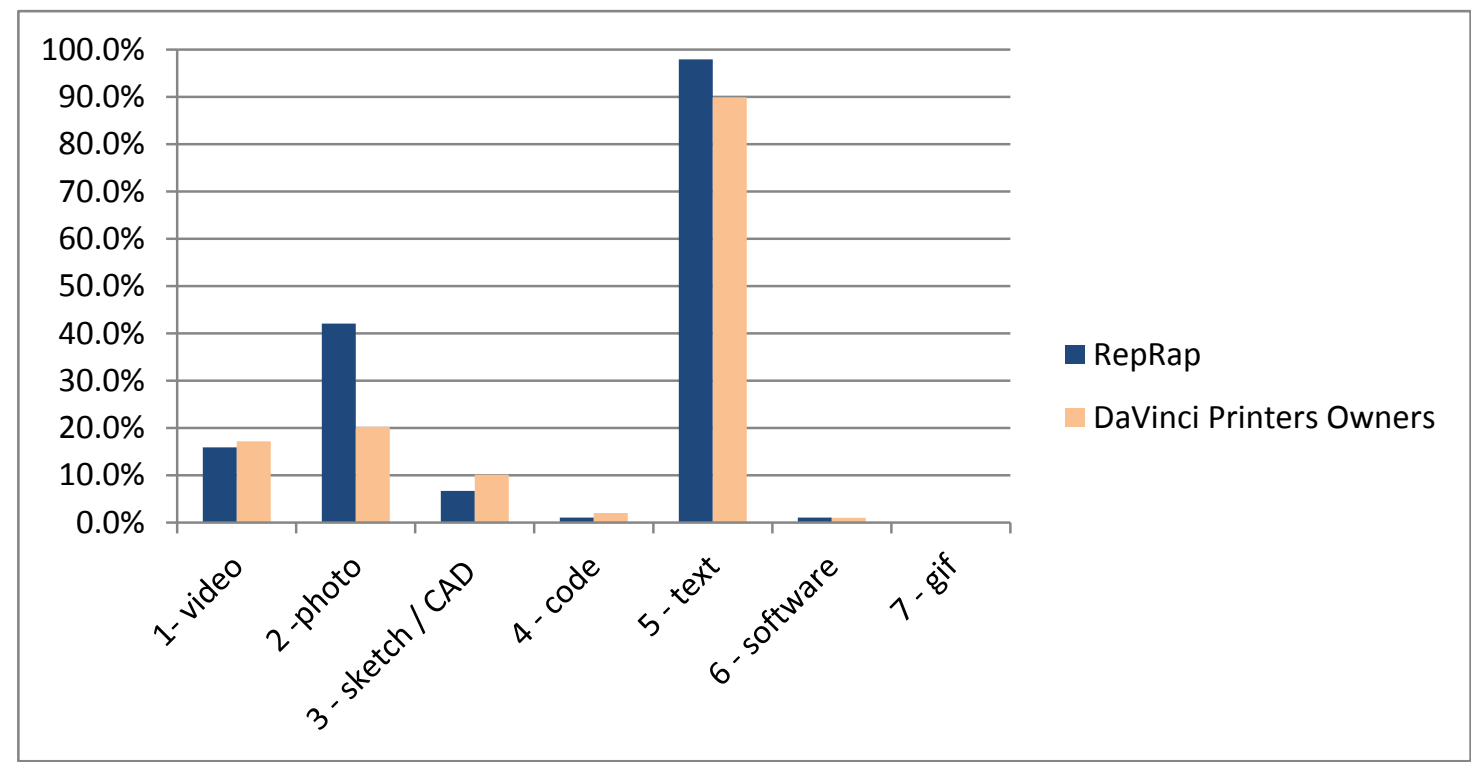

Figure 5. Frequency of BO's uses Thingiverse

The H2 are elaborated: H2- The frequency of BO's types and the detail level, in distinct platforms, is not similar between projects from academic and non-academic OSDs. The Table 1 summarizes these results the analysis of BO's usage in projects. The table presents the number of: photos, number of sketch/CAD, code lines, characters and links, it is possible to note a relevant difference.

Table 1. Frequence of BO's usage classified by type in each platform

\begin{tabular}{|l|l|l|l|c|c|c|r|r|r|}
\hline & Repository & $\begin{array}{l}\text { N. of } \\
\text { videos }\end{array}$ & $\begin{array}{l}\text { N. of } \\
\text { photos }\end{array}$ & $\begin{array}{c}\text { N. of } \\
\text { sketch/CAD }\end{array}$ & $\begin{array}{l}\text { N. of } \\
\text { code } \\
\text { lines }\end{array}$ & $\begin{array}{c}\text { N. of } \\
\text { characters }\end{array}$ & $\begin{array}{c}\text { N. of } \\
\text { software }\end{array}$ & $\begin{array}{r}\text { N. of } \\
\text { gif }\end{array}$ & $\begin{array}{r}\text { N. of } \\
\text { others } \\
\text { links }\end{array}$ \\
\hline A & $\begin{array}{l}\text { RepRap- } \\
\text { Wiki }\end{array}$ & 1 & 5 & 42 & 628 & 19920 & 2 & 0 & 21 \\
\hline B & $\begin{array}{l}\text { RepRap - } \\
\text { Thingiverse }\end{array}$ & 0 & 0 & 6 & 0 & 395 & 0 & 0 & 0 \\
\hline C & $\begin{array}{l}\text { DaVinci } \\
\text { Thingiverse }\end{array}$ & 0 & 0 & 7 & 0 & 3290 & 0 & 0 & 0 \\
\hline
\end{tabular}

The Project A (OSD academic) is available on wiki. It contains a significant distinction between remaining despite the level of detail. It contains 42 CAD documents and 628 code lines, 19920 characters in texts, 2 software and 21 links. About the links it was observed that 10 links to community's wiki, 1 link to Thingiverse, 4 link to kitbom, 3 link to github, 1 link to mendelmax, 1 link to a blog, 1 link to store. All these other repositories with more structured and complex data 
It is interesting too that there was not founded significative distinction between Projects B and C. This could mean that repository influences the sharing information, as expected, and that more academic community prefer other repositories in order to look for more detailed data.

From this analysis, the following five characteristics emerged.

1. Communication. The OSD community, in general, uses objectivity in the BOs. The text is short and the number of documents is synthesized. On the other hand, OSD Academic Spin-off community cares about the detail of the project.

2. Purpose. The ease to replicate is the goal of OSD community. The OSD Academic Spin-off community also considers the ease to replicate, however the methodological support have a high degree of importance and they look for complementary information about project details. This is observed in the line codes number.

3. Structure of information. The use of repositories as Thingiverse promotes to OSD community the agility. The members find easily the content and replicate. The OSD Academic Spin-off promotes an understanding of what is the project and how to do. To detail this information they promote redundancy.

4. Target-audience. The use of repositories as Thingiverse or a wiki show a difference between the people that access the content. The target-audience of OSD community can be anyone, amateurs or specialists, for example. On the other hand, the OSD Academic Spin-off community has as main target-audience technicians. It is not habitual to see amateurs in the forum discussions as wiki. The members have a basic knowledge about the project.

5. Success of the project. This characteristic is measure by the number of "mades" in the OSD community while in the OSD Academic Spin-off community; the success can be seen through the number of interactions in the forums, in this case it seems to be no concern with what would be a measure of success.

\section{CONCLUSION}

Based on the survey and the case studies, we have identified the hypothesis that five different characteristics, as indicated in Table 2, should be expected in communities with academic background.

Table 2. Differences between the characteristics of OSD community and OSD Academic

\begin{tabular}{l|cr}
\hline & OSD community & OSD Academic \\
\hline Communication & Objectivity & detailing \\
\hline Purpose & easy to replicate & methodological support \\
\hline Structure of information & promote agility & promote redundancy \\
\hline Target-audience & Anyone & anyone and technicians \\
\hline Success of the project & number of made & number of interactions
\end{tabular}

Evidence that communities are limited by functionalities faults was found with this research. There were not significant differences between projects at the same platform, indicating the influence of repositories, and changing the collaboration. Nevertheless, academic OSD, concerned with specialized audience, combine and complement these resources using other platforms in order to surpass this limitation and providing more detailed information.

This is evidence that these communities are demanding new and more advanced platforms and probably functions like versioning and other are important. Note, for example, the case of RepRap making use of GitHub, a Versioning Control System.

The research suggests that repository's functionalities predispose the differences between the contents. All the repositories analysed are open and free, so the choice of the repository already shows characteristics that the community values.

The open repositories have functionalities that allow the use of friendly BO's: videos, photos and accelerated videos (Affonso and Amaral, 2015; Bonvoision and Boujut, 2015). However, it was observed that these are little explored by studied communities, whether they are academic or nonacademic. For example, if the academic community would like to disseminate knowledge and the product replication, it should focus on the user who is a specialist or amateur/hobbyist and they should consider the use of redundancy, promoting agility and simplicity by exploring the friendly BO's. 
It is important to note that this study was exploratory and has important limitations. The case studies were based in only three projects in function of the time spent to read an access all documents. The number of projects in phase one was representative but was based in only one platform. It could be replicable in others to obtain more reliable data.

Future research seeking a larger sample on case studies and more platforms are needed. It is also suggested as future research: a full study about BOs for in-depth analysis in OSD communities; a study about the little use of video and photos in communities OSD and the predominant use of texts.

\section{REFERENCES}

Affonso, C.A.C. and Amaral, D.C. (2015), "Boundary objects in Open Source Design: experiences from OSE community", International Conference on Engineering Design 2015, ICED 2015, Proceedings of the 20th International Conference on Engineering Design. Milan, Italy, Vol. 8, pp. 447-456.

Benkler, Y. (2006), The wealth of networks: how social production transforms markets and freedom, Yale University Press, New Haven and London.

Bonvoisin, J. and Boujut, J. F. (2015), “Open design platforms for open source product development: current state and requirements", International Conference on Engineering Design 2015, ICED 2015, Proceedings of the 20th International Conference on Engineering Design, Milan, Italy, Vol. 8, pp. 11-22.

Broberg, O., Andersen, V. and Seim, R. (2011), "Participatory ergonomics in design processes: The role of boundary objects", Applied Ergonomics, Vol. 42 No. 3, pp. 464-472.

Bruijn, E. (2010), "On the viability of the Open Source Development model for the design of physical objects: lessons learned from the RepRap project", Master in Science, University of Tilburg.

Carlile, P.R. (2002), "A Pragmatic View of Knowledge and Boundaries”, Organization Science.

De Jong, J. P. and De Bruijn, E. (2013), "Innovation lessons from 3-D printing." MIT Sloan Management Review, Vol. 54 No. 2, pp. 43.

Etzkowitz, H. (2008), "The Triple Helix: University-Industry-Government Innovation in Action”, Vol. 42 No. 3, Routledge, New York and London.

Fuggetta, A. (2003), "Open source software an evaluation.” Journal of Systems and Software, Vol. 66, pp. 77-90.

Füller-seitz, G. and Reger, G. (2010), Networking beyond the software code? an explorative examination of the development of an open source car project. Technovation, Vol. 30 No. 11-12, 627-634.

Panchal, J.H. and Fathianathan, M. (2008), "Product realization in the age of mass collaboration." ASME 2008 International Design Engineering Technical Conferences \& Computers and Information in Engineering Conference. Brooklyn, August 3-6, Design Engineering Division and Computers in Engineering Division, New York, pp. 1-11.

Pérez, M.P. and Sánchez, A.M. (2003), "The development of university spin-offs: early dynamics of technology transfer and networking", Technovation, Vol. 23 No. 10, pp. 823-831.

Pinfield, S. (2009), Journals and repositories: An evolving relationship? Learned Publishing, Vol. 22 No. 3, pp. 165-175. doi: http://doi.org/10.1087/2009302

Pinfield, S., et al. (2014), "Open-access repositories worldwide, 2005-2012: Past growth, current characteristics, and future possibilities", Journal of the Association for Information Science and Technology, Vol. 65 No. 12, pp. 2404-2421.

Reprap Wiki (2015), Available: http://reprap.org/wiki/00str00der. (Acessed date 18-jul-2016).

Santoso, S.M. and Wicker, S.B. (2014). The future of three-dimensional printing: Intellectual property or intellectual confinement? new media \& society, p. 1461444814538647.

Shane, S. (2004), Academic Entrepreneurship: University Spinoffs and Wealth Creation, Edward Elgar, pp. 352.

Star, S.L. and Griesemer, J.R. (1989), "Institutional Ecology, Translations' and Boundary Objects: Amateurs and Professionals in Berkeley's Museum of Vertebrate Zoology", Journal Social Studies of Science, Vol. 19 No. 3, pp. 387-420.

Sánchez, A.M. and Pérez, M.P. (1995), "University-industry relationships in peripheral regions:the case of Aragon in Spain", Technovation, Vol. 15 No. 10, pp. 613-625.

Suber, P. (2012), Open access, MIT Press, Cambridge and Massachussetts.

Thingiverse (2016a), Available: http://www.thingiverse.com/thing:702060 (accessed date 15-ago-2016)

Thingiverse (2016b), Available: http://www.thingiverse.com/thing:1723817 (accessed date 25-nov-2016)

Van der Sijde, P., et al. (2008), Teaching entrepreneurship: cases for education and training. Springer Science $\&$ Business Media.

Wenger, E. (2000), "Communities of practice and social learning systems". Organization, Vol. 7 No. 2, pp. 225-246. 


\section{ACKNOWLEDGMENTS}

We would like to thanks Federal Institute of Education, Science and Technology of Sao Paulo (IFSP) for academic training program and the referees that generously support us with fruitful recommendations. 